\title{
Systemic sarcoidosis initially presenting as an orbital tumour
}

\author{
M. Faller*, A. Purohit*, N. Kennel**, F. de Blay*, J. Sahel**, G. Pauli*
}

Systemic sarcoidosis initially presenting as an orbital tumour. M. Faller, A. Purohit, N. Kennel, F. de Blay, J. Sahel, G. Pauli. CERS Journals Ltd 1995.

ABSTRACT: A 73 year old woman presented with redness, itching and painless proptosis of the left eye.

Clinical examination and computed tomographic (CT) scan of the orbit revealed a postero-ocular mass, the biopsy of which showed a noncaseating, giant cellular, epithelioid granuloma compatible with sarcoidosis. The patient had no respiratory complaints, but the thoracic CT scan showed multiple bilateral hilar and mediastinal adenopathies. Gallium scan showed increased uptake in both hilar regions, in the left orbit and in the right parotid gland. Multiple bronchial biopsies revealed sarcoid granulomas, with a bronchoalveolar lavage (BAL) cytological pattern of active sarcoidosis. The evolution was favourable with prednisolone given at a dose of $0.5 \mathrm{mg} \cdot \mathrm{kg}^{-1}$ daily.

It is suggested that in an unusual presentation of sarcoidosis, a thorough search should be made for localization at other sites, lungs in particular, even in the absence of respiratory complaints.

Eur Respir J., 1995, 8, 474-476.
*Service de Pneumologie, and **Clinique Opthalmologique, Hôpital Civil, Strasbourg, France.

Correspondence: G. Pauli

Service de Pneumologie

Hôpital Civil

B.P. 426

67091 Strasbourg Cédex

France

Keywords: Ocular sarcoidosis

ocular tumour

systemic sarcoidosis

Received: May 241994

Accepted after revision October 181994
Sarcoidosis is a multisystem granulomatous disorder of unknown aetiology most commonly affecting young adults, and presenting most frequently with bilateral hilar lymphadenopathy, with or without pulmonary infiltrates and skin or eye lesions [1]. Although virtually any part of the visual apparatus may be affected [2], orbital sarcoidosis taking the form of a tumour, without eyelid, eyeball or lacrymal gland involvement, is rare [3-5].

We report a case of systemic sarcoidosis that initially presented as an orbital tumour.

\section{Case report}

A 73 year old obese woman with recently detected non-insulin-dependent diabetes presented with redness and itching of the left eye of 3 months' duration. Treatment for conjunctivitis had proved useless. The patient was referred to the ophthalmological clinic. On examination, the left conjunctiva was red and chemotic. There was proptosis of the left eye, with a Hertel exophthalmometer reading of $24 \mathrm{~mm}$, and the ocular movements were diminished in all directions, without diplopia. A firm to hard, nonreducible and nontender mass was palpable on the medial sides of the superior and inferior parts of the orbital cavity. Visual acuity of the left eye was $8 / 10$, and that of the right eye was 10/10. There was no evidence of uveitis, and ocular tension was normal in both eyes. On fundoscopy, papillary congestion with hypervascularity was seen in the left eye, which was confirmed by angio-fluoro-retinography. Goldman's perimetry did not show any defects in visual fields.
Computed tomographic (CT) scan of the orbits showed a posterio-ocular mass extending to medial and superior regions and probably invading the left optic nerve (fig. 1). There was no osteolytic lesion. Magnetic resonance imaging (MRI) of the orbit showed that the posterior ocular mass surrounded the left optical nerve, without invasion. Based upon these clinicoradiological findings, left orbital lymphoma was highly suspected. Biopsy

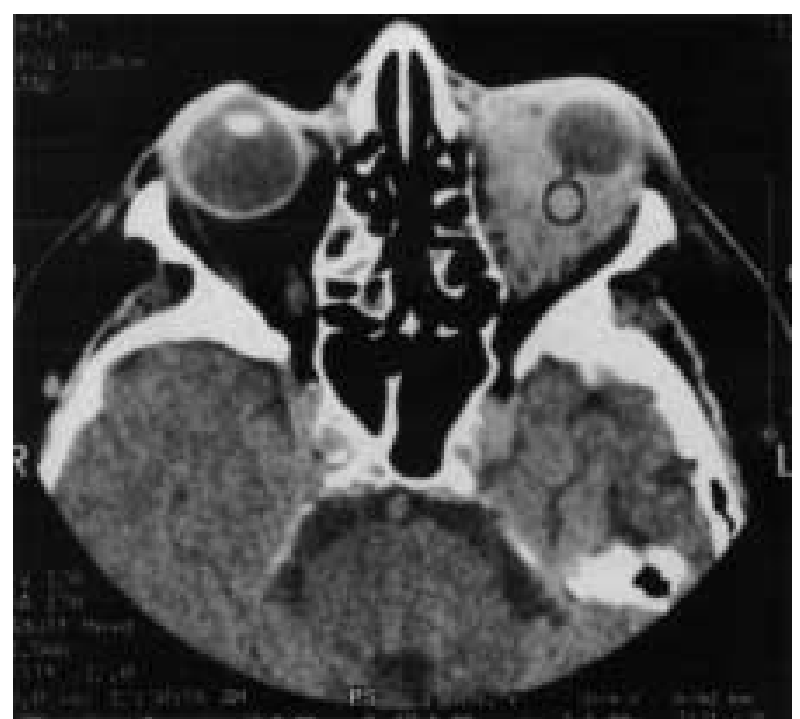

Fig. 1. - Computed tomographic scan of the orbits, showing left postero-ocular mass without osteolytic lesion. 


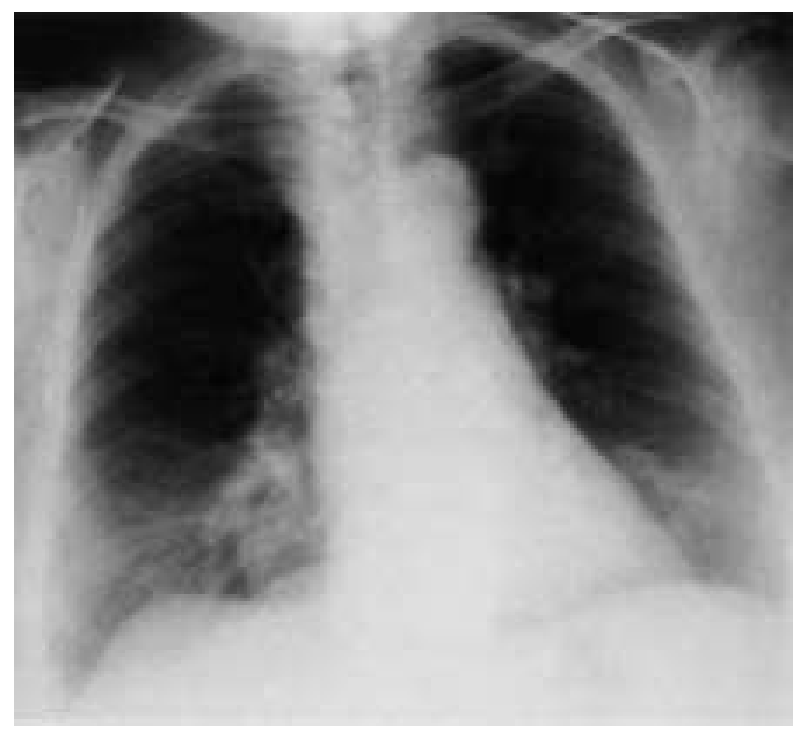

Fig. 2. - Right hilar adenopathy on chest roentgenogram at admission.

of the tumour did not show lymphoma, but a noncaseating giant cellular epithelioid granulomatous inflammation characteristic of sarcoidosis. Although an initial chest roentgenogram was found to be normal, the patient was transferred to the chest clinic of the University Hospital of Strasbourg to complete the assessment of possible thoracic involvement of sarcoidosis.

The patient had no respiratory complaints with the exception of mild exertional dyspnoea of grade I/IV, which could be attributed to her obesity. Clinically, she was in good general health, afebrile, with a pulse rate of 80 beats $\cdot \mathrm{min}^{-1}$, a blood pressure of $110 / 50 \mathrm{mmHg}$, and a respiratory rate of 20 breaths $\cdot \mathrm{min}^{-1}$. There was no palpable lymphadenopathy or hepatosplenomegaly. Parotid glands were not enlarged. A right facial nerve paralysis was noted on neurological examination.

Laboratory studies showed a normal haemogram and the erythrocyte sedimentation rate (ESR) was raised to $32 \mathrm{~mm}$ in the first hour. C-reactive protein (CRP), liver and renal function tests were normal. There was no hypercalcaemia. Angiotensin converting enzyme was raised to $37.4 \mathrm{nmol} \cdot \mathrm{min}^{-1} \cdot \mathrm{ml}^{-1}$ (normal $22.9 \pm 5.7$ ). Arterial blood gases in room air at rest were: arterial oxygen tension $\left(\mathrm{PaO}_{2}\right) 10.2 \mathrm{kPa}(76.8 \mathrm{mmHg})$, arterial carbon dioxide tension $\left(\mathrm{PaCO}_{2}\right) 5.2 \mathrm{kPa}(39.3 \mathrm{mmHg}), \mathrm{pH} 7.42$, and arterial oxygen saturation $\left(\mathrm{SaO}_{2}\right)$ of $96 \%$. Intradermal tuberculin test with $0.1 \mathrm{ml}$ of $10 \mathrm{IU}$ purified protein derivative (PPD) was negative. On a repeat chest roentgenogram (fig. 2), right hilar adenopathy was suspected, and was confirmed by tomograms. Thoracic CT scan showed multiple bilateral hilar and mediastinal lymphadenopathies, without any parenchymal lesion (fig.3). Electrocardiography (ECG), echocardiography, and abdominal ultrasound examinations were normal. Pulmonary function test values (expressed in percentage of predicted) were as follows: forced vital capacity (FVC) $93 \%$, forced expiratory volume in one second $\left(\mathrm{FEV}_{1}\right) 89 \%$, $\mathrm{FEV}_{1} / \mathrm{FVC} 79 \%$, total lung capacity (TLC) $93 \%$, residual

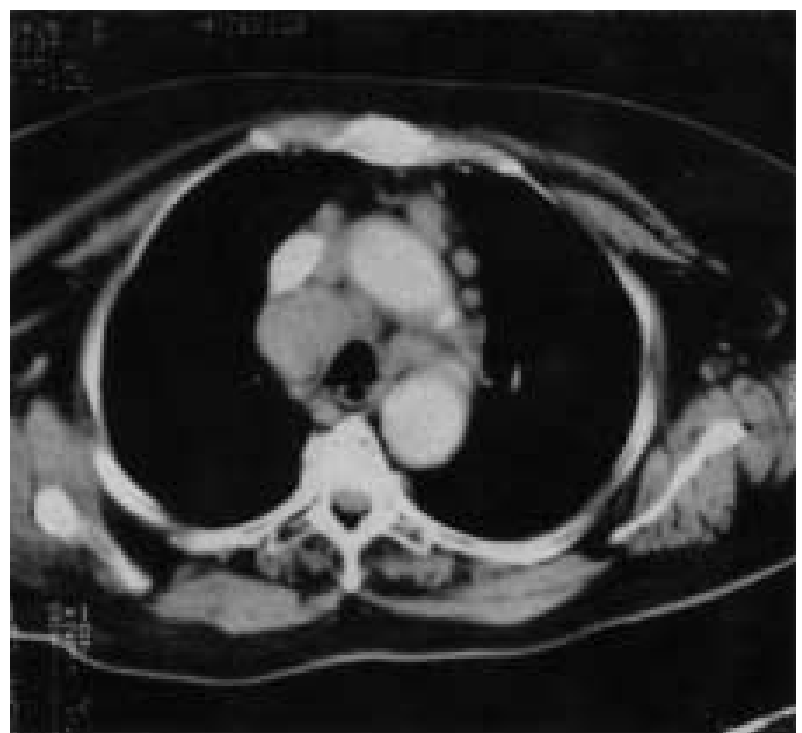

Fig. 3. - Thoracic computed tomographic scan below the level of the aortic arch, showing multiple bilateral mediastinal lymphadenopathies.

volume (RV) $98 \%$ with $\mathrm{RV} / \mathrm{TLC}$ ratio of $42 \%$ (normal $36 \%$ ). Transfer capacity of the lungs for carbon monoxide (TLCO) was normal.

Gallium 67 scan showed concentration of the isotope in both hilar regions, in the left orbit and in the right parotid gland. Fibreoptic bronchoscopic examination revealed an inflammatory tracheobronchial mucosa, with slight broadening of all bronchial biopsies. Histopathological examination of multiple biopsies showed non-caseating, giant cellular, epithelioid granulomas. Bronchoalveolar lavage cytological examination showed hypercellularity with $76 \%$ lymphocytes, $22 \%$ macrophages, and $2 \%$ eosinophils. CD4/CD8 ratio was 8 .

Thus, the final diagnosis of multisystem sarcoidosis was retained. With respect to the patient's obesity and diabetes, a low dose oral corticotherapy consisting of prednisolone, $0.5 \mathrm{mg} \cdot \mathrm{kg}^{-1}$ daily was started. After one month of treatment, exophthalmus was improved. Herter exophthalmometer reading was now $23 \mathrm{~mm}$. There was significant improvement in facial paralysis. One year later, exophthalmus has disappeared, as have the mediastinal lymph nodes. Corticosteroid therapy was progressively tapered and no relapse was observed when the daily dose reached $0.2 \mathrm{mg} \cdot \mathrm{kg}^{-1}$.

\section{Discussion}

The visual system is involved in more than a quarter of sarcoidosis cases [6], the main manifestations being anterior and posterior granulomatous uveitis. The retroocular optic pathway is often affected, along with the central nervous system [7]. Outside the lacrymal gland, sarcoidosis presenting as an orbital mass is a rare condition [3]. The two first cases of orbital sarcoidosis were reported by HoLm [8] and KING [9]. Among over 1,000 cases of primary orbital tumour, BENEDICT [10] found 
only two cases of sarcoidosis involving the skin of the eyelids and the orbit.

In several cases of orbital sarcoidosis reported in the literature, thoracic involvement by sarcoidosis was not mentioned or not found [3,8-11]. In a study of 15 cases with histologically identified orbital sarcoidosis, CoLLISON et al. [2] found that 14 also had sarcoidosis lesions in other organs, and they stressed the point that a search for other system involvement should be made.

Other cases of orbital sarcoidosis reported radiographic chest abnormalities suggestive of sarcoidosis: mediastinal and hilar adenopathies [4, 12-15], and pulmonary infiltrates [16]. The diagnosis was only confirmed histologically in two studies, by bronchoscopic biopsy [5, 17], and mediastinoscopic biopsy [5]. In our case, we obtained histological proof of pulmonary localization, and found a typical pattern of active sarcoidosis in bronchoalveolar lavage analysis, with predominance of lymphocytes $(76 \%)$ and an increase in CD4/CD8 ratio.

Multisystem spread of sarcoidosis in orbital sarcoid tumour has been suspected in osseous lesions [4]. In our case, significant deposition of gallium in the right parotid gland, and mediastinal and left orbital gallium uptake also suggested involvement by sarcoidosis, which was possibly the cause of the facial paralysis.

Although sarcoidosis usually affects younger patients, review of the literature stresses that the cases of sarcoidosis with orbital involvement are predominantly females over 50 yrs of age. Clinically, orbital sarcoidosis presents as a rapidly progressing, usually nontender pseudotumour with possible exophthalmus $[16,18]$ and limitation of ocular movements, and might be mistaken for a malignant orbital tumour. The diagnosis is generally provided by ocular tumour biopsy, but a systematic search for sarcoid involvement in other sites, lungs in particular, should be carried out. As a roentgenogram might be interpreted as normal when hilar lymph nodes are only slightly enlarged, we consider that CT scan is useful for confirmation of thoracic localizations.

In the absence of confirmed systemic sarcoidosis, reported cases of solitary ophthalmological sarcoidosis can only be accepted reluctantly, as granulomas might be reactions directed against bacteria, fungi or foreign bodies, causing similar histological abnormalities [19, 20].

Orbital sarcoidosis should be treated with corticosteroids. Extirpation, which has been tried unsuccessfully in the past $[10,17]$, is technically difficult because of the infiltrating nature of the tumour [4]. Surgery may result in deformities of the orbit, and there have been local relapses.

\section{References}

1. James DG. Sarcoidosis and other granulomatous disorders. In: Lung Biology in Health and Disease. 73. New York, M. Dekker Inc., 1994; p. 859.

2. Collison JMT, Miller NR, Green WR. Involvement of orbital tissues by sarcoid. Am J Ophthalmol 1986; 102: 302-307.

3. Stein HA, Henderson JW. Sarcoidosis of the orbit. Am J Ophthalmol 1956; 41: 1054-1056.

4. Francois J, Hanssens M, Verbraeken H. Sarcoidose orbitaire. J Fr Ophtalmol 1978; 1: 461-464.

5. Leino M, Tuovinen E, Romppanen T. Orbital sarcoidosis: a case report. Acta Ophthalmol 1982; 60: 809-814.

6. Obenauf CD, Shaw HE, Sydnor CF, Klintworth GK. Sarcoidosis and its ophthalmic manifestations. Am J Ophthalmol 1978; 86: 648-655.

7. Sahel J, Flament J, Buchheit F, Bronner A. Problèmes posés par la sarcoidose des voies optiques. Ophtalmologica 1986; 193: 213-224.

8. Holm E. A case of sarcoid of Boeck. Acta Ophthalmol Kbh 1937; 15: 235-238.

9. King MJ. Ocular lesions of Boeck's sarcoid. Trans Am Ophthalmol Soc 1939; 37: 442-458.

10. Benedict WL. Sarcoidosis involving the orbit. Arch Ophthalmol 1949; 42: 546-550.

11. Jensen VJ. Sarcoidosis of the orbit. Acta Ophthalmol Kbh 1957, 35: 416-419.

12. Kaplan M. Boeck's sarcoid: report of a case with an unusual precipitating factor. Am J Ophthalmol 1948; 31: 83-85.

13. Nichols CW, Mishkin M, Yanoff M. Presumed orbital sarcoidosis: report of a case followed by computerized axial tomography and conjunctival biopsy. Trans Am Ophthalmol Soc 1978, 76: 67-75.

14. Imes RK, Reifschneider JS, O'Connor LE. Systemic sarcoidosis presenting initially with bilateral orbital and upper lid masses. Ann Ophthalmol 1988; 20: 466-469.

15. Cordier J, Floquet J, Raspiller A, Galoisy CH. Localisations tumorales orbitaires de la maladie de Besnier-BoeckSchaumann. Bull Soc Ophtalmol France 1971; 71: 499-502.

16. Appelmans M, Michiels J, Nelis J, Dieryck FA. Nouvelle observation de pseudotumeur de l'orbite par sarcoidose de Besnier-Boeck-Schaumann. Bull Soc Belge Ophtalmol 1968; 149: 541-558.

17. Urvoy M, Garrec A, Dary J, Belloir D, Chesnais A, Ardouin M. La place de la sarcoidose dans l'etiologie des exophtalmies unilatérales. Bull Soc Ophtalmol Fr 1973; 73: 581-587.

18. Satorre J, Ante M, Rootmaln J. Orbital lesions with granulomatous inflammation. Can J Ophthalmol 1991; 26: 174-195.

19. Garner A. Pathology of pseudotumours of the orbit: a review. J Clin Pathol 1973; 26: 639-648.

20. Jacobiec FA. The orbit. In: Spencer WH, ed. Ophthalmic Pathology. An Atlas and Textbook. 3rd edn. Philadelphia, W.B. Saunders Co., 1986; pp. 2730-2736. 